\title{
El docente como decisor en la apropiación de las tecnologías digitales para la intervención didáctica: los beneficios de la soberanía tecnológica desde el paradigma libre
}

\author{
The teacher as a decision maker in the appropriation of digital technologies \\ for didactic intervention: the benefits of technological sovereignty based on \\ the free paradigm \\ O professor como decisor na apropriação das tecnologias digitais para \\ intervenção didática: os benefícios da soberania tecnológica do paradigma livre
}

\author{
Santiago Marcelo Álvarez \\ Instituto Superior del Profesorado Tecnológico (ISPT) \\ Córdoba, Argentina \\ santiago.ma.alvarez@gmail.com \\ (D) ORCID: https://orcid.org/0000-0002-5106-945X
}

Recibido - Received - Recebido: 28 / 06 / 2021 Corregido - Revised - Revisado: 19 / 09 / 2021 Aceptado - Accepted - Aprovado: 30 / 09 / 2021

DOl: https://doi.org/10.22458/ie.v23iespecial.3608

URL: https://revistas.uned.ac.cr/index.php/innovaciones/article/view/3608

\begin{abstract}
Resumen: El presente ensayo propone la lectura analítica del papel que cumplen las decisiones teórico- metodológicas del profesorado en la selección y la apropiación de las tecnologías digitales en las intervenciones didácticas. Básicamente, se coloca en relieve el concepto de "soberanía tecnológica" en los procesos educativos, en el cual el rol de las personas docentes resulta crucial para favorecer marcos de referencia de "paradigmas libres" en tecnología, en la enseñanza y el aprendizaje. Se realiza un recorrido conceptual sobre la idea de "curador de contenidos", desde el papel de la persona que enseña y el acento se coloca sobre la noción de medios digitales en los escenarios de educación. Dentro de los marcos referenciales sobre la libertad tecnológica, se proponen dos miradas: "Software libre" y "Recursos Educativos Abiertos", como propiciadores de la construcción de soberanía tecnológica en el interior de las construcciones didácticas, las cuales se despliegan en los espacios que configuran la praxis docente. En última instancia y de manera breve, se concluye el ensayo al reflexionar sobre el lugar preponderante que debe asumir el profesor que selecciona y combina materiales educativos en sus construcciones didácticas.
\end{abstract}

Palabras claves: soberanía tecnológica; tecnología educacional; digitalización; enseñanza; educación; método de enseñanza.

Summary: This essay proposes the analytical reading of the role played by the theoretical-methodological decisions of the teaching staff in the selection and appropriation of digital technologies in didactic interventions. Basically, the concept of "technological sovereignty" is highlighted in educational processes, in which the role of teachers is crucial to favor frameworks of "free paradigms" in technology, in teaching and learning. A conceptual journey is travelled based on the idea of "content curator", based on the role of the person who teaches and the accent is placed on the notion of digital media in educational settings. Within the referential frameworks on technological freedom, two perspectives are proposed: "Free Software" and "Open Educational Resources", as promoters of the construction of technological sovereignty within the didactic constructions, which are displayed in the spaces that they configure the teaching praxis. Ultimately and briefly, the essay is concluded by reflecting on the preponderant place that the teacher must assume who selects and combines educational materials in their didactic constructions.

Key Words: technological sovereignty; educational technology; digitization; teaching; education; teaching method. 
Resumo: Este ensaio propõe uma leitura analítica do papel das decisões teóricas e metodológicas dos professores na seleção e apropriação das tecnologias digitais em intervenções didáticas. Basicamente, destaca o conceito de "soberania tecnológica" nos processos educacionais, no qual o papel dos professores é crucial para favorecer estruturas de "paradigmas livres" em tecnologia, ensino e aprendizagem. Uma visão conceitual é feita da ideia de "curador de conteúdo", a partir do papel da pessoa que ensina e a ênfase é colocada na noção de mídia digital em cenários educacionais. Dentro das estruturas referenciais da liberdade tecnológica, duas perspectivas são propostas: "Software Livre" e "Recursos Educacionais Abertos", como viabilizadores da construção da soberania tecnológica dentro das construções didáticas, que são implantadas nos espaços que compõem a práxis do ensino.Por último e brevemente, o ensaio conclui com uma reflexão sobre o lugar determinante que deve ser assumido pelo professor que seleciona e combina materiais educacionais em suas construções didáticas.

Palavras-chave: Soberania tecnológica; tecnologia educacional; digitalização; ensino; educação; método de ensino.

\section{INTRODUCCIÓN}

Las tecnologías digitales habilitan la creación y el uso de contenidos educativos basados en múltiples narrativas y lenguajes hipermediales (contenido visual, audiovisual, contenido web, textual, interactivo, contenido gamificado. La gamificación se la describe como el proceso de pensamiento de juego y sus mecanismos para atraer a los usuarios e incitarlos a resolver problemas (Zichermann y Cunningham, 2011).

La gamificación incorpora elementos del diseño del juego para aprovecharlos en el contexto educativo. Esto significa que no se trata de utilizar juegos en sí mismos, sino tomar algunos de sus principios o mecánicas, tales como: los puntos o incentivos, la narrativa, la retroalimentación inmediata, el reconocimiento, la libertad de equivocarse, entre otros, para enriquecer la experiencia de aprendizaje (Deterding et al., 2011; Kim, 2015), que no son meramente basados en la apología de una técnica; más bien habilitan nuevos soportes de la cultura que se sustenta en la búsqueda, exploración, creación y producción de contenidos, con nuevas formas de expresión y pensamiento: el hipertexto e hipermedia son conceptos y no productos. (Baricco, 2019)

Uno de los aspectos nodales para considerar estas producciones, tiene un vínculo con "pensar la dimensión ética y política del uso de software como herramienta educativa" si se parte del rol que juegan las personas educadoras. Por ello, en el siguiente ensayo, se plantea el abordaje de la dimensión teórica del concepto soberanía tecnológica desde una perspectiva general y aplicada a la educación. Luego, posicionar el rol de la persona docente como "curador" de contenidos digitales en los propios procesos de enseñanza y aprendizaje en las intervenciones escolares de la cotidianidad. Para ello, partir de los enfoques del "Software Libre" y "REA (Recurso Educativo Abierto)" como movimientos conceptuales que suponen cierta noción de soberanía tecnológica para contribuir en las acciones de los docentes, formando sus criterios en las decisiones pedagógicas, metodológicas y didácticas.

En último lugar, se realizarán consideraciones en relación con el uso y la apropiación de aplicaciones, situados en los beneficios de utilizar el paradigma libre en tecnología para la propia realidad educativa y la praxis docente. 


\section{DESARROLLO}

\section{De la conceptualización de soberanía tecnológica en general a la soberanía tecnológica en educación}

El término soberanía o soberano proviene del latín superanus, el cual tiene el prefijo super que significa "encima de" y el sufijo anus "perteneciente a", "procedente de" o en "relación con" (Bordignon, 2016, p. 3). Por tanto, en el campo de la tecnología, el constructo teórico "soberanía tecnológica" arroja algunos indicios para reflexionar acerca del "poder o la capacidad sobre" las tecnologías. Más precisamente, como indica Bordone (2020), se refiere a "la posibilidad o la capacidad que tienen las personas de elegir, producir, intervenir las tecnologías".

Se define, entonces, soberanía tecnológica como el derecho de los pueblos para "desarrollar su propia tecnología con origen y destino en la sociedad civil". (Haché, 2014).

Hablar de "Soberanía Tecnológica" permite reflexionar en el cambio de rol que debe asumir; es decir, sirve para dejar de ser únicamente consumidores y pasar a ser prosumidores (productores y consumidores). En otras palabras, equilibrar aquellas iniciativas, para que de este modo se pueda fomentar la transformación social del conocimiento: "Se intenta abarcar un empoderamiento hacia el conocimiento mismo de la tecnología, dejar de ser únicamente un consumidor para pasar a ser un productor y así poder generar los elementos tecnológicos necesarios para el desarrollo social y tecnológico necesario". (Educ.ar, 2021)

Por tanto, al situarse en los escenarios educativos, es notable comprender que

[...] cada vez que seleccionamos una herramienta para nuestras clases, estamos posicionándonos no solo como curadores del uso de dicha herramienta, sino que debemos pensar en su implementación integral dentro del aula, cómo afectará la formación de nuestros estudiantes, cuál es el "costo real" de su utilización con respecto a la entrega de datos privados a empresas, la dependencia tecnológica, la obsolescencia programada por parte de los proveedores de soluciones técnicas, entre otras cuestiones. (Basel, V. y Equipo de producción de materiales educativos en línea, 2020)

Interpelar la educación con la lectura conceptual de la soberanía tecnológica, permitirá adoptar una multiplicidad de miradas, las cuales posibilitan habilitar espacios formativos en el sistema educativo formal, en todos los niveles, con el fin de propiciar el desarrollo y la promoción de la expresión/creación colectiva por medio de tecnologías digitales, lo cual dotará de cierta fluidez tecnológica a la niñez y la adolescencia; quienes las podrán usar para la gestión, la administración o las comunicaciones, y, por ello, se configuran como un elemento esencial de empoderamiento de la sociedad.

\section{El rol de la persona docente como decisora de herramientas digitales en procesos de enseñanza y aprendizaje}

Las tecnologías digitales en las praxis educativas de las personas docentes, inevitablemente están surcadas por un sinnúmero de condicionamientos, requerimientos y criterios. La inclusión genuina de tecnologías (Maggio, 2012) en los escenarios escolares, por parte del profesorado es una tarea de decisión muy particular; pues debe reunir posicionamientos sólidos sobre la soberanía tecnológica en el uso de herramientas digitales que fomenten un empoderamiento socio-cultural para el estudiantado. 


\section{Docente como decisor, como "curador digital"}

En este sentido, se comprende a "la educación como un campo de tensiones sobre el que operan intereses de diversos tipos de discursos sobre las tecnologías en la escuela entendida como uno de los espacios, donde estos intereses se cristalizan" (Montero, 2019) y el rol docente toma lugar como decisor de tecnologías para sus clases. Decisor, en tanto como sujeto imbricado en la tríada didáctica, es quien "decide". Esta acción debe, ineludiblemente estar acompañada por posicionamientos teóricos, para decidir en cuestiones fundamentales. De acuerdo con lo anterior, la persona docente como decisora puede adoptar una o varias estrategias relacionadas con las tecnologías para la educación.

Por otra parte, la metáfora de curador de contenidos digitales resulta interesante para dar cuenta del desafío de seleccionar, organizar y dar sentido a los contenidos digitales que podemos encontrar en internet, servidores y diversos dispositivos de almacenamiento.

En tal caso, la persona docente se configura como aquel agente especializado, pues un intermediario crítico del conocimiento (Reig, 2010), en la búsqueda, exploración, selección y sistematización tanto de herramientas digitales para la educación como los contenidos específicos que competen a su campo disciplinar.

Es interesante, remarcar que:

[...] la Curación de contenido digital es una actividad relativamente nueva, que emerge como práctica de especialización y especificidad temática, con el rigor de la selección y criterios de experticia.

Básicamente es el acto interactivo de investigar, hallar, filtrar, organizar, agrupar, integrar, editar y compartir el mejor y más relevante contenido de un tópico específico en una significativa colección digital online, que podría ser importante para un grupo de gente cuyo sentido del aprendizaje puede ser actualizado en torno a ese tópico. (Posada, 2013, p. 3)

Este proceso de curación y decisión que realizan las personas docentes se define como una actividad, la cual propicia la especialización temática mediante la selección de contenido, la reinterpretación de usos del medio digital y la convergencia de medios-soporte. (Posada, 2013)

Los medios digitales son las herramientas, los recursos y el software pensados para la educación. Principalmente, los educadores deben colocar su atención en ese proceso de decisorio para planificar sus construcciones didácticas mediadas por tecnologías. (Edelstein, 2005)

El profesorado que asume el compromiso de exploración, selección y apropiación de medios digitales para sus clases, ineludiblemente pone en juego múltiples decisiones que lo convierten en un "curador de contenidos". Por ello, se afirma que la persona docente es decisora, en tanto que selecciona los recursos educativos necesarios que favorezcan el fortalecimiento pedagógico-didáctico en su área disciplinar.

Según lo anterior expuesto, la Tecnología Educativa, como campo de estudio nutrida por las Ciencias de la Educación, ofrece un panorama interesante, para analizar el papel relevante que tienen las tecnologías en los procesos educativos. Por ello, reflexionar sobre el rol docente como curador de contenido, invita a rastrear criterios, marcos conceptuales y líneas teóricas para fundamentar las acciones en la práctica docente concreta. 


\section{Las herramientas y medios digitales en el rol decisor docente}

Los nuevos medios digitales son los medios de comunicación que se basan en un soporte digital y tienen características comunes como la programabilidad y la reducción de la información a bits, esto es unidades uniformes que pueden contener sonido, texto o imágenes en una combinación de registros inédita en la historia humana. Estos nuevos medios incluyen las computadoras, los celulares, las redes sociales, las cámaras y los videos digitales así como los videojuegos, entre otros. (Dussel, 2012)

En este marco se define a las herramientas digitales desde la perspectiva que propone Dussel (2012, 2018 , 2019) para abordarlas como medios que se inscriben en una trama compleja entre su infraestructura tecnológica, permisibilidades técnicas y los protocolos de uso, con sus códigos, expectativas y definiciones sobre los productores y usuarios.

El principal acento, en este complejo entramado de recursos y condiciones técnicas, está dado por el rol sustancial de la persona docente; pues al final es quien decide las herramientas más propicias para generar espacios de enseñanza y aprendizaje. Y, por sobre todos los elementos, conocer las consideraciones en el uso y el manejo de ellas en y para la educación.

Por lo anterior, es interesante resaltar que es potente el aprovechamiento de recursos adaptables a las necesidades con intencionalidad pedagógica, y no meramente un método de aplicación práctico e instrumental.

\section{La persona docente como decisora de tecnologías para la educación desde el paradigma libre}

Aquí, se tomará como recomendación, adoptar dos movimientos conceptuales, los cuales servirán como andamio para caminar y favorecer los procesos de enseñanza y aprendizaje. Se comenta de: "Software libre" y "Recursos Educativos Abiertos (REA)".

En primer lugar, es importante destacar que el

[...] software libre es un movimiento que comenzó en 1983 cuando Richard Stallman anunció el proyecto GNU, en contraposición con la aparición de monopolios artificiales en el desarrollo de software. Se podría decir que la meta del movimiento fue dar libertad a los usuarios de programas de computadoras reemplazando el software con términos de licencias restrictivas (software privativo) por una alternativa libre (Basel, V. y Equipo de producción de materiales educativos en línea, 2020)

Un software libre tiene como rasgo característico la idea de "libertad". Es decir, la comunidad de usuarios pueda ejecutar, copiar, estudiar, mejorar y redistribuir el software. Por tanto, libertad de usar el programa para cualquier propósito, de estudiar cómo funciona y adaptarlo a las diferentes necesidades, distribuir copias, poder mejorarlo y hacer públicas las mejoras. (Adell \& Bernabé, 2007)

La utilización de software libre, contribuye en gran medida a la soberanía tecnológica, puesto que permite estudiar y modificar el software -en los casos que se tenga conocimiento sobre lenguaje de programación en el código fuente-; pero además, se puede agregar contenido, o modificar el contenido existente, siempre se deben tener en cuenta los marcos legales en los cuales están inmersos esos contenidos, a la vez poder compartir esa información o contenido y las mejoras realizadas, de la misma manera en como se pudo acceder a ese contenido. 
Desde la dimensión socio-política, el SL ofrece una alternativa a favor de la soberanía e independencia tecnológica de los países de la periferia que, como la Argentina, deben asegurar su autonomía en materia de información (uno de los recursos sociales en juego en el capitalismo informacional actual) a través de la construcción de respuestas locales a problemas locales. Es decir que la libre circulación del conocimiento y los derechos humanos asociados al acceso a la cultura, son la base de su potencial emancipador. (Xhardez, V., 2014)

En políticas educativas, es un desafío para los Estados preguntarse cómo llevar adelante el software libre, con el fin de empoderar la soberanía tecnológica sin menoscabar otros derechos humanos como la propiedad intelectual, pero a la vez alcanzar un conocimiento sostenible que beneficie al bien común de toda su población.

Las personas docentes necesitan decidir, de manera criteriosa, cómo se realiza el ingreso, uso y apropiación de la tecnología a las aulas; es decir, en qué sentido se está promoviendo el uso del software y hardware libre, especialmente en el sistema educativo, dado que es un requisito básico en el camino para lograr la soberanía tecnológica.

Por otra parte, los REAs son otro movimiento sustancial en la adopción e inclusión genuina de tecnologías para la educación.

El término REA fue acuñado por la Unesco y se define por sus siglas como "recursos educativos abiertos", con el objetivo de ofrecer, de forma abierta, recursos educativos provistos por medio de las TIC para su consulta, uso y adaptación con fines no comerciales. (Basel, V. y Equipo de producción de materiales educativos en línea, 2020)

\section{El Servicio de Formación en Red de INTEF (2014) considera que:}

El término Recursos Educativos Abiertos designa a materiales de enseñanza, aprendizaje e investigación en cualquier soporte, digital o de otro tipo, que sean de dominio público o que hayan sido publicados con una licencia abierta que permita el acceso gratuito a esos materiales, así como su uso, adaptación y redistribución por otros sin ninguna restricción o con restricciones limitadas. (p.4)

Hablar de recursos educativos abiertos, es posicionarse en el paradigma tecnológico libre -tal como indica Pagola (2020) en el [Canal del ISEP]. Básicamente, implica mencionar la reutilización de contenidos ya creados, práctica que es muy común en el ámbito educativo cuando, como curadores de contenidos, el profesorado toma información de distintas fuentes (algunas propias, otras de internet, por ejemplo) para generar y crear nuestras clases o documentos para compartir con nuestros/as estudiantes.

Por ello, es primordial contar con un marco regulatorio que permita la copia, la modificación y la consiguiente redistribución por parte de las comunidades docentes; esto se constituye en uno de los pilares de los recursos educativos abiertos (REA). Tal es así que, el requisito de tener una licencia específica; es decir, licencias libres para estar resguardados legalmente.

Lo anterior comentado permitirá que se traslade en paradigmas libres tecnológicos en educación, y pensar la dimensión ética y política del uso de software como herramienta educativa desde el rol como profesorado. 


\section{Beneficios y ventajas del uso pedagógico de softwares libres educativos y REA}

Luego de explicitar los componentes conceptuales de los dos movimientos sustentados desde el paradigma de tecnología libre, es importante remarcar los beneficios que aporta el considerar estas herramientas en nuestras prácticas educativas, y más aún, en las decisiones pedagógicas intervinientes.

El Centro Nacional de Referencia de Aplicación de las TIC (Gobierno del Gran Canarias, s.f.) basada en fuentes abiertas (CENATIC) ha elaborado un decálogo con las diez razones por las cuales debe utilizarse software libre en las escuelas. En esta ocasión se efectuará una selección sobre aquellas que se consideren más significativas y valorables para el uso libre de tecnologías para la educación.

Realizo esta elección valiéndome del concepto de soberanía tecnológica y, asimismo, se argumenta que el estudiantado necesita formarse en competencias que promuevan el aprendizaje compartido, autónomo y, por sobre todos los aspectos, desde las tecnologías. Nótese la selección:

- Contribuye a formar personas libres, independientes, críticas y autónomas.

- Permite enseñar con herramientas adaptadas a la realidad del estudiantado.

- Crea una comunidad de conocimiento compartido.

- Facilita que el estudiantado disponga en su casa de las mismas herramientas educativas que utilizan en su centro, de forma $100 \%$ legal.

Por otro lado, en cuanto a la utilización de Recursos Educativos Abiertos (REA) es potente resaltar cómo ha beneficiado a los educadores; pues a menudo se realizan materiales que luego se comparten con colegas $y$, tanto el método científico como las revisiones por pares se basan en fundamentos similares a la colaboración abierta. La novedad de esta iniciativa radica en la facilidad con la cual, gracias a las TIC, los REAs pueden generarse, distribuirse a audiencias masivas por medio de Internet y la seguridad legal que las licencias gratuitas y de contenido abierto proporcionan a autores y usuarios. (Eduteka, 2007)

Luego de este breve recorrido sobre las ventajas de uso de estas herramientas tecnológicas libres en el ámbito de la educación, resulta válido aclarar que en Argentina se cuenta con repositorios de REA para las lecciones, y sobre todo se puede decidir, seleccionar y reunir ciertos criterios para lograr intervenciones educativas potentes, con el fin de propiciar una cultura de producción y circulación del conocimiento libre.

\section{SÍNTESIS Y REFLEXIONES FINALES}

Luego de hacer dialogar el término de "Soberanía Tecnológica" con el rol que ocupan el profesorado al momento de seleccionar, decidir o elegir las herramientas digitales para sus procesos de enseñanza y aprendizaje, he desarrollado un "camino" reflexivo sobre la importancia de la inclusión genuina de Software libres y REAs en las clases o encuentros educativos con tecnologías.

El papel crucial como "decisor" de la persona docente de los procesos de enseñanza y aprendizaje, tan complejos en las praxis pedagógico-didácticas actuales, necesita inevitablemente estar acompañado con un corpus teórico sólido el cual oficie de piso, centrado en paradigmas abiertos del uso y apropiación de contenidos de aprendizaje, herramientas/software para la creación, entrega, uso y mejora del contenido de aprendizaje abierto y recursos de implementación (licencias de derechos de autor que promuevan la publicación abierta de materiales, principios de diseño y adaptación local de contenido). 
Por ello, si se coloca en relieve la responsabilidad y el compromiso que asumen las personas docentes al momento de explorar, buscar, seleccionar y combinar diferentes tipos de materiales educativos digitales, se constituyen en "curadores de contenido", de acuerdo con múltiples aspectos y criterios que luego se conjugan en la construcción singular de una "clase". Para ello, Fernández, P., Arévalo, E. y Equipo de producción de materiales educativos en línea (2021) en su propuesta de conceptualización ofrecen una serie de criterios que orientan en el desarrollo del proyecto como curadores de contenido, los cuales se montan cuando se decide el conjunto de recursos, herramientas, materiales, y modos/estrategias para las intervenciones didácticas.

Las autoras señalan que:

[...] cuando pensamos en la selección de materiales para trabajar con los alumnos, hay una primera base general que enmarca esa búsqueda y que tiene que ver con la propuesta de enseñanza en sí: la naturaleza del contenido a enseñar, las decisiones conceptuales, metodológicas y comunicacionales, las características de los destinatarios, los propósitos y los objetivos de enseñanza y aprendizaje, etc. (Fernández, P., Arévalo, E. y Equipo de producción de materiales educativos en línea, 2021, p.1)

Por otro lado, según la idea sobre el proceso de curación de contenidos que llevan a cabo el profesorado, resulta interesante notar las decisiones conceptuales y metodológicas que se abordan cuando se trabaja el universo de las imágenes en nuestras producciones educativas. Es decir qué lugar juegan las imágenes, sus interpretaciones y las lecturas en los contenidos que se proponen en las clases. Para eso es interesante proponer al estudiantado el análisis crítico en el uso, la apropiación y la manipulación de imágenes, fotografías, y todo tipo de contenido visual. Se requiere como personas que enseñan, guiar en la reflexión de contenidos que se sustenten en el paradigma libre. ¿Por qué es importante? Porque tal como aporta Fontcuberta, J. (2016):

La omnipresencia de cámaras, pantallas e imágenes crece al compás de esa trepidación martilleante de más, más y más, hasta que la abundancia alcanza tal exceso que provoca una explosión. Entonces, debemos plantearnos si esa caterva desenfrenada de fotografías no constituye en realidad una especie de metástasis. (p.23)

El lugar de los contenidos visuales dentro y fuera de la escuela es una marea de información que agolpea, como señala el autor, a tal punto que provoca una explosión. Se considera que la labor en la educación es, no eliminar esas producciones, sino más bien co-construir con el estudiantado, criterios, consejos, recomendaciones y modos de producir, "leer", interpretar imágenes, desde la idea de soberanía tecnológica, al considerar los recursos digitales abiertos, para poder efectuar libremente estas acciones mencionadas. Es decir, colocar marcos de referencias que les sirvan a nuestros niños/as adolescentes y jóvenes a ser prosumidores críticos de las tecnologías.

Resulta ser este desafío, un cambio sustancial en el abordaje del conocimiento que circula en el interior de nuestras aulas, tanto físicas como virtuales. Para ello, el imperativo hoy es enfatizar en la formación docente continua en estas temáticas emergentes en el campo de las tecnologías digitales y educación.

Para alcanzar lo anterior mencionado, se necesita puntualizar las capacitaciones docentes en alfabetización digital crítica, con el fin de buscar que el aprendizaje y el desarrollo de la apropiación de herramientas digitales que promuevan la co-creación y desarrollo de la creatividad, estimulen la participación activa en el proceso de construcción de recursos creativos que induzcan al estudiantado a participar de su proceso de aprendizaje de una forma más interactiva y participativa. 
Adell, J. y Bernabé, Y. (2007). Software libre en educación. Tecnología educativa. Madrid: McGraw-Hill, pp. 173-195.

Baricco, A. (2019). The Game. Barcelona, Anagrama.

Basel, V. y Equipo de producción de materiales educativos en línea (2020). Recursos educativos abiertos. Seminario de Narrativas Hipermediales. Ciclo de seminarios Tecnologías Digitales y Educación. Córdoba: Instituto Superior de Estudios Pedagógicos. Ministerio de Educación de la Provincia de Córdoba.

Basel, V. y Equipo de producción de materiales educativos en línea (2020). Software libre. Seminario de Narrativas Hipermediales. Ciclo de seminarios Tecnologías Digitales y Educación. Córdoba: Instituto Superior de Estudios Pedagógicos. Ministerio de Educación de la Provincia de Córdoba.

Basel, V. y Equipo de producción de materiales educativos en línea (2020). Soberanía tecnológica. Seminario de Narrativas Hipermediales. Ciclo de seminarios Tecnologías Digitales y Educación. Córdoba: Instituto Superior de Estudios Pedagógicos. Ministerio de Educación de la Provincia de Córdoba.

Bordignon, F. (2016). Soberanía tecnológica y educación: una dupla indisoluble. Prólogos. Revista de Historia, Política y Sociedad, (7):79-102.

Canal ISEP (2020). Tecnologías Digitales y Educación -Seminario de Narrativas Hipermediales - Entrevista - Lila Pagola. [Material de video] Disponible en: https://www.youtube.com/ watch?v=ELTWnruEXaY (Consultado 10/05/2021)

Canal ISEP (2020). Tecnologías Digitales y Educación -Seminario de Narrativas Hipermediales Entrevista - Matías Bordone. [Material de video] Disponible en: https://www.youtube.com/ watch?v=jGBLAgkllB8 (Consultado 8/05/2021)

Deterding, S., Dixon, D., Khaled, R., y Nacke, L. (2011). From game design elements to gamefulness: Defining "gamification". En Memorias del 15th International Academic MindTrek Conference: Envisioning Future Media Environments, pp. 9-15. doi:10.1145/2181037.2181040

Dussel, I. (2012). La formación docente y la cultura digital: Métodos y saberes para una nueva época. En A. Birgin (Comp.), Más allá de la capacitación. Debates acerca de la formación de los docentes en ejercicio. Buenos Aires: Paidós.

Dussel, I. y Trujillo Reyes, B. (2018). ¿Nuevas formas de enseñar y aprender? Las posibilidades en conflicto de las tecnologías digitales en la escuela. Perfiles educativos, (40):1-48.

Edelstein, G. (2005). Enseñanza, políticas de escolarización y construcción didáctica. En Frigerio G. Diker $\mathrm{G}$ (comps.), Educar: ese acto político. Bs. As: del estanque editorial.

Educ.ar (2021). ¿Por qué es importante la soberanía tecnológica? Disponible en: https://www.educ.ar/ recursos/155423/por-que-es-importante-la-soberania-tecnologica

Eduteka (2007). Recursos Educativos Abiertos (REA). Recuperado de http://www.eduteka.org/OER.php (Consultado 25/05/2021)

Fernández, P., Arévalo, E. y Equipo de producción de materiales educativos en línea. (2021). Conceptualización. Discusiones oportunas para hablar de la curaduría de materiales digitales. Laboratorio: Curaduría de Materiales Digitales. Actualización Académica Enseñar con Herramientas Digitales. Córdoba: ISEP - Ministerio de Educación de la Provincia de Córdoba.

Fontcuberta, J. (2016). La furia de las imágenes. Notas sobre la postfotografía. Barcelona: Galaxia Gutenberg. 
Gobierno de Canarias. (s.f.). El software libre en educación. Disponible: http://www3.gobiernodecanarias.org/medusa/contenidosdigitales/FormacionTIC/cdtic2014/02cc/33_el_software_libre_en_ educacin.html (Consultado 14/05/2021)

Haché, A. (2014). Soberanía tecnológica. Ritimo, (1):9-16.

Maggio, M. (2012). Enriquecer la enseñanza. Los ambientes con alta disposición tecnológica como oportunidad. Buenos Aires: Paidós

Montero, J. (2019). Parada 1 - Exploración. Laboratorio Los medios y la regulación de la enseñanza. Parada exploración. Especialización Docente de Nivel Superior en Educación y Medios Digitales. Córdoba: Instituto Superior de Estudios Pedagógicos - Ministerio de Educación de la Provincia de Córdoba.

Posada, M. (2013). Curaduría de contenidos digitales: Un potencial para la Educación y el Aprendizaje. En: XIV Encuentro Internacional Virtual Educa. Colombia 2013.

Reig, D. (2010). Content Curator, Intermediario Crítico del Conocimiento: Nueva profesión para la Web 3.0.disponible en http://www.dreig.eu/caparazon/2010/01/09/content-curatorweb-3/ Consultado [28/06/2021].

Servicio de Formación en Red. INTEF. (2014). REA. Recursos Educativos Abiertos para la enseñanza de las Ciencias Sociales. Bloque 1: Introducción a los Recursos Educativos Abiertos.

Xhardez, V. (2014). Contribuciones del software libre a la soberanía tecnológica y los desafíos futuros. Voces en el Fénix. Disponible en: https://www.vocesenelfenix.com/content/contribuciones-delsoftware-libre-la-soberan\%C3\%ADa-tecnol\%C3\%B3gica-y-los-desaf\%C3\%ADos-futuros 